\title{
Insights into the Melipona scutellaris (Hymenoptera, Apidae, Meliponini) fat body transcriptome
}

\author{
Cristina Soares de Sousa ${ }^{1}$, José Eduardo Serrão ${ }^{2}$, Ana Maria Bonetti ${ }^{1}$, Isabel Marques Rodrigues Amaral $^{1}$, \\ Warwick Estevam Kerr ${ }^{1}$, Andréa Queiroz Maranhão ${ }^{3}$ and Carlos Ueira-Vieira ${ }^{1}$ \\ ${ }^{1}$ Laboratório de Genética, Instituto de Genética e Bioquímica, Universidade Federal de Uberlândia, \\ Uberlândia, $M G$, Brazil. \\ ${ }^{2}$ Departamento de Biologia Geral, Centro de Ciências Biológicas e da Saúde, \\ Universidade Federal de Viçosa, Viçosa, MG, Brazil. \\ ${ }^{3}$ Departamento de Biologia Celular, Universidade de Brasília, Brasília, DF, Brazil.
}

\begin{abstract}
The insect fat body is a multifunctional organ analogous to the vertebrate liver. The fat body is involved in the metabolism of juvenile hormone, regulation of environmental stress, production of immunity regulator-like proteins in cells and protein storage. However, very little is known about the molecular mechanisms involved in fat body physiology in stingless bees. In this study, we analyzed the transcriptome of the fat body from the stingless bee Melipona scutellaris. In silico analysis of a set of cDNA library sequences yielded 1728 expressed sequence tags (ESTs) and 997 high-quality sequences that were assembled into 29 contigs and 117 singlets. The BLAST X tool showed that $86 \%$ of the ESTs shared similarity with Apis mellifera (honeybee) genes. The M. scutellaris fat body ESTs encoded proteins with roles in numerous physiological processes, including anti-oxidation, phosphorylation, metabolism, detoxification, transmembrane transport, intracellular transport, cell proliferation, protein hydrolysis and protein synthesis. This is the first report to describe a transcriptomic analysis of specific organs of $M$. scutellaris. Our findings provide new insights into the physiological role of the fat body in stingless bees.
\end{abstract}

Keywords: fat body, gene expression, Melipona, stingless bees, transcriptome.

Received: September 18, 2012; Accepted: March 11, 2013.

The insect fat body is a diffuse organ that fills the body cavity and consists of mesodermal cells known as trophocytes or fat body cells (Arrese and Soulages, 2010; Roma et al., 2010). In addition to trophocytes, bees contain oenocytes, another cell type of ectodermal origin found scattered throughout the fat body (Paes de Oliveira and Cruz-Landim, 2003; Martins et al., 2011a,b; Price et al., 2011).

The insect fat body is a multifunctional organ with a role in a variety of metabolic processes, including: a) storage of proteins, lipids and carbohydrates, which are precursors for metabolism in other organs, b) regulation of chemical compounds released in the haemolymph, c) synthesis of vitellogenin and d) synthesis of antimicrobial peptides that act in the innate immune response (Cruz-Landim, 1985; Tzou et al., 2002; Andrade et al., 2010, 2011; Ottaviani et al., 2011).

Send correspondence to Carlos Ueira-Vieira. Laboratório de Genética, Instituto de Genética e Bioquímica, Bloco 2E, Sala 226, Universidade Federal de Uberlândia, Campus Umuarama, 38400-902 Uberlândia, MG, Brazil. E-mail: ueira@ingeb.ufu.br.
Gene expression, assessed via transcriptomic analysis, can provide insights into animal biology and physiology since changes in gene expression may reflect genetic responses to environmental stimuli, as well as immune responses. Expressed sequence tags (ESTs) provide a fast, accurate tool for gene identification and are widely used in functional genomic studies (Adams et al., 1991; Zweiger and Scott, 1997; Martins et al., 2011b).

Melipona scutellaris is a stingless bee found in northeastern Brazil. Populations of this bee have decreased substantially as a consequence of human activity (Kerr et al., 1996) and studies of this species are important for its maintenance.

Workers of $M$. scutellaris were obtained from the stingless bee colony at the Institute of Genetics and Biochemistry, Federal University of Uberlandia, State of Minas Gerais, Brazil. Foraging workers were identified by the presence of pollen in the pollen sacs and were collected when returning to the hive. The abdomens of 15 foragers were opened with forceps while submerged in insect saline solution $\left(0.1 \mathrm{M} \mathrm{NaCl}, 0.1 \mathrm{M} \mathrm{KCl}, 0.1 \mathrm{M} \mathrm{CaCl}_{2}\right)$ and the fat 
body layers under the tergites and sternites were separated, transferred to liquid nitrogen and stored at $-80{ }^{\circ} \mathrm{C}$.

mRNA was purified using a Micro-FastTrack 2.0 mRNA isolation kit (Invitrogen) and used to synthesize the first strand of cDNA. A cDNA library of the M. scutellaris fat body was constructed using a SuperScript Plasmid System kit with Gateway Technology for cDNA Synthesis and Cloning (Invitrogen). The clones were sequenced using DYEnamic ET Dye Terminator Cycle Sequencing for MegaBace DNA Analysis Systems kits (GE Healthcare) according to the manufacturers recommendations and analyzed with a MegaBace 1000 sequencer (Amersham Biosciences).

The computer program EGassembler from the $\mathrm{Hu}$ man Genome Center was used to trim the vector and mitochondrial sequences. Phred (Ewing and Green, 1998; Ewing et al., 1998) and Base Caller Cimarron v.3.12 softwares were used to identify high-quality sequences (Phred $>20$ and $\geq 150$ base pairs) that were assembled using CAP3. The high-quality sequences were compared using the algorithms BLAST X and BLAST N v.2.2.25 with an initial E-value threshold of $10^{-6}$ (Altschul et al., 1990, 1997). Gene Ontology and FatiGO tools were used to assign possible biological functions to the fat body transcripts based on comparison with Drosophila proteins, as described by AlShahrour et al. (2004).

A total of $2.26 \times 10^{5}$ clones were obtained from the fat body cDNA library. The length of randomly cloned cDNAs was determined by agarose gel electrophoresis; the fragment size varied from 150 to 2000 base pairs (data not shown).

The fat body cDNA sequences yielded 1728 ESTs and 997 high quality reads longer than $150 \mathrm{bp}$, totaling 197,904 nucleotides. Of the 997 high quality reads, 392 (39.3\%) ESTs were from mitochondrial genes and the remaining $605(60.7 \%)$ were edited and assembled into 29 contigs and 117 singlets. Seventy-one percent of the ESTs showed matches with the transcriptome shotgun assembly from Melipona quadrifasciata obtained by Woodard et al. (2011). The ESTs identified here were deposited in dbEST under accession numbers HO000185-HO000320 and HO000363-HO000419.

Nearly $40 \%$ of the $M$. scutellaris fat body ESTs were of mitochondrial origin and are likely also found in the fat body of Aedes aegypti (Feitosa et al., 2006). The number of mitochondria per cell increases 700 fold in newly emerged adult insects (Kurella et al., 2001), suggesting that the mitochondria of fat body cells are an important source of energy for adult bees. In bees, the fat body plays a role in protein synthesis and storage (Ivanova and Staikova, 2007) and, in agreement with this, we found transcripts involved in protein synthesis.

The M. scutellaris fat body ESTs showed $86 \%$ similarity with Apis mellifera genes and the remaining 14\% with Nasonia vitripennis, Drosophila melanogaster and others (Figure 1). Of the two hymenopteran species, $A$. mellifera is phylogenetically closer to M. scutellaris than N. virtripennis (The Honeybee Genome Sequencing Consortium, 2006; Nasonia Genome Working Group, 2010).

The comparison of contigs and singlets with their respective orthologs in D. melanogaster showed that the transcripts identified in M. scutellaris fat bodies were associated with known biological processes, cellular components and molecular functions (Figure 2). The main functions of these proteins were anti-oxidation, phosphorylation, metabolism, detoxification, transmembrane transport, intracellular transport, cell proliferation, protein hydrolysis and protein synthesis. The contigs were assembled from overexpressed genes and most were found to encode proteins with roles in cell metabolism (Table 1). These data agree with the physiological role of the insect fat body (Price et al., 2011).

The BLASTX and BLASTN analyses identified sequences homologous to proteins associated with the immune response (Toll proteins, kinases and cytochrome P450), resistance to insecticides, cell cycle control, juvenile hormone metabolism and resistance to environmental stress.

The insect fat body is an organ of the immune system and we identified ESTs related to the immune response in the fat bodies of M. scutellaris, e.g., Toll and other genes, as well as genes for cytochrome P450 and kinases. Martins et al. (2011a) found $P 450$ in A. aegypti oenocytes, a cell type

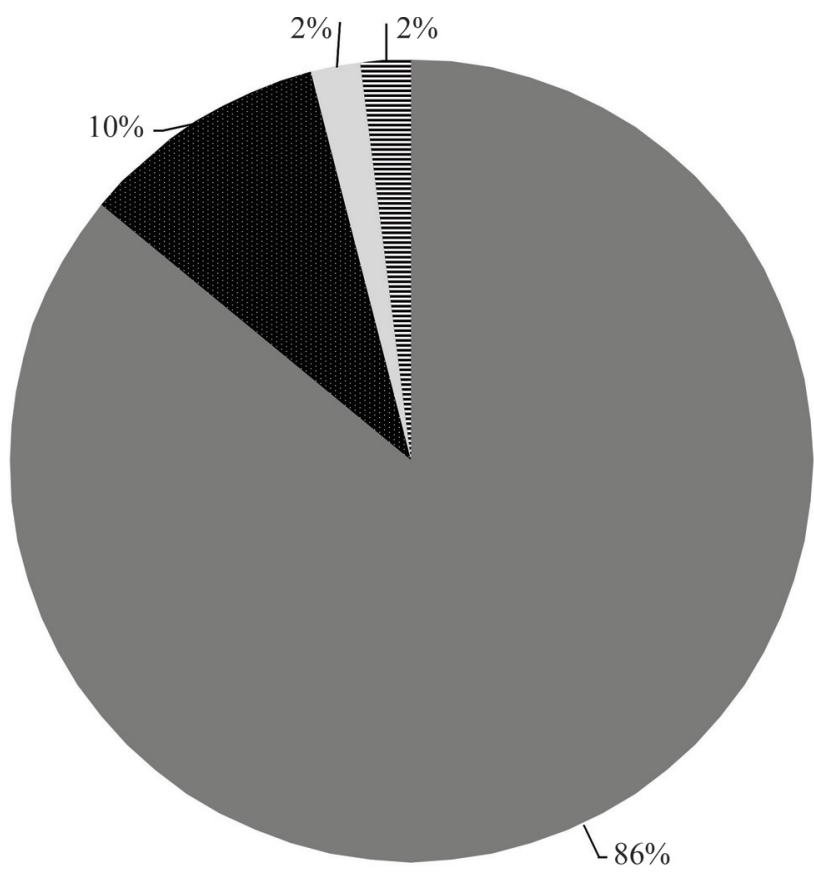

- Apis mellifera Nasonia vitripennis $₫$ Other = Drosophila

Figure 1 - Transcript distribution of the best matches of the Melipona scutellaris fat body cDNA library. The best matches were listed based on the insect species without considering E-values. 
scattered amongst trophocytes in bees. Insects are resistant to infection by microorganisms, although an acquired immune system is lacking. The immune response of insects consists of an innate immune system in which microorgan- isms and molecules are recognized by specific receptors, thereby activating the cellular immune response associated with phagocytosis, encapsulation and humoral responses (Ribeiro and Brehélin, 2006; Andrade et al., 2010). Hemo-

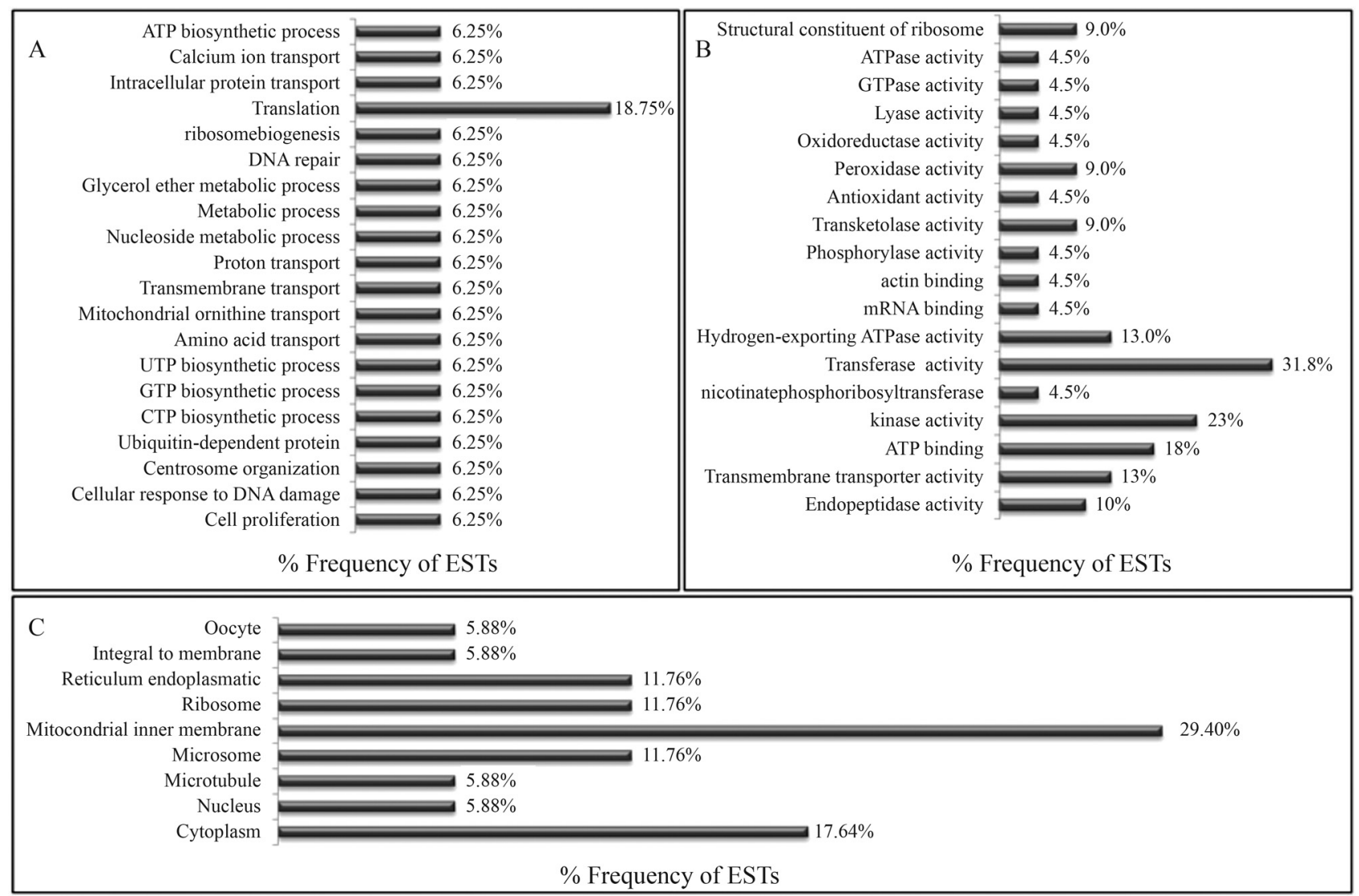

Figure 2 - Transcript distribution of Melipona scutellaris fat body cDNA library. Protein functions were assigned based on homology with Drosophila genes. (A) Biological process. (B) Molecular function. (C) Cell component.

Table 1 - Best matched Melipona scutellaris contigs from BlastN analysis. The Melipona contig ID is the access number in GenBank. Only sequences that matched the insect sequence are shown.

\begin{tabular}{llcc}
\hline Melipona contig ID & Best match & E-value & Identity (\%) \\
\hline HO000238.1 & PREDICTED: similar to CG7530-PA, isoform A [Apis mellifera] & $4.00 \mathrm{E}-18$ & 90 \\
HO000202.1 & PREDICTED: similar to CG4692-PB, isoform B [Apis mellifera] & $1.00 \mathrm{E}-46$ & 68 \\
HO000240.1 & PREDICTED: similar to translationally controlled tumor protein [Nasonia vitripennis] & $9.00 \mathrm{E}-15$ & $1.00 \mathrm{E}-10$ \\
HO000411.1 & PREDICTED: similar to F27C1.2a [Apis mellifera] & $2.00 \mathrm{E}-19$ & 54 \\
HO000230.1 & PREDICTED: similar to CG10672-PA [Apis mellifera] & $3.00 \mathrm{E}-11$ & 63 \\
HO000262.1 & PREDICTED: similar to CG3271-PB, isoform B [Apis mellifera] & $3.00 \mathrm{E}-33$ & 79 \\
HO000263.1 & PREDICTED: Apis mellifera putative fatty acyl-CoA reductase CG5065-like & $3.00 \mathrm{E}-16$ & 72 \\
HO000317.1 & Heat shock protein 90 [Apis mellifera] & $2.00 \mathrm{E}-71$ & $5.00 \mathrm{E}-10$ \\
HO000312.1 & PREDICTED: similar to R04B5.5 [Apis mellifera] & $4.00 \mathrm{E}-18$ & 58 \\
HO000199.1 & PREDICTED: similar to sentrin/sumo-specific protease senp7 [Nasonia vitripennis] & $4.00 \mathrm{E}-34$ & 64 \\
HO000273.1 & PREDICTED: similar to serine/threonine-protein kinase rio1 [Nasonia vitripennis] & $4.00 \mathrm{E}-54$ & 700 \\
HO000373.1 & Farnesoic acid o-methyltransferase-like isoform 1 protein [Melipona scutellaris] & 70 \\
HO000393.1 & PREDICTED: similar to microsomal glutathione S-transferase-like & $6.00 \mathrm{E}-06$ & 53 \\
HO000389.1 & CG1742-PA, isoform A isoform 1 [Apis mellifera] &
\end{tabular}


cytes are cells that play a role in the cellular immune response of insects and have been described in M. scutellaris larvae (Amaral et al., 2010).

Insects can recognize specific microbial markers known as pathogen-associated molecular patterns (PAMPs). PAMPs are recognized by pattern recognition receptors (PRR) that mediate cellular immune responses such as phagocytosis and the serine-proteinase cascade that activates melanization and/or the release of antimicrobial substances (Kavanagh and Reeves, 2004). A PRR found in insects is Toll, a transmembrane receptor with a leucinerich extracellular domain and an intracellular region similar to the interleukin-1 receptor (Leclerc and Reichhart, 2004). Toll receptors recognize lipids, carbohydrates, peptides and nucleic acids from different invaders (Akira et al., 2006).

Amongst the M. scutellaris fat body ESTs, $23 \%$ were for kinases, mainly mitogen-activated protein kinases (MAP-kinases). Protein kinases (PKs) play a central role in signal transduction, including the transmission of environmental stimuli, the coordination of intracellular processes and in invertebrate defense against pathogens (Kim et al., 2002; Wojda et al., 2004; Chen Chih et al., 2007). In addition, MAP-kinases, such as p42/44 ERK, p38 MAPK, JNK, PKA, PKB, PKC and Akt are involved in the control of cell apoptosis (Cross et al., 2000).

Among the transcripts identified in this study we found an EST that encoded cytochrome P450 (CYP6g2), a family of enzymes with multiple functions (Mansuy, 1998). Although numerous $P 450$ isoforms have been identified in insects, with an average of 80-120 isoforms per individual (Tijet et al., 2001), A. mellifera has only 46 genes that encode P450 proteins (Claudianos et al., 2006). In Drosophila, the genes Cyp12d1, Cyp6g1 and Cyp6g2 are associated with resistance to DDT, neonicotinoids and growth regulators (Daborn et al., 2007). In the $M$. scutellaris fat body, the EST that encoded for P450 was an ortholog of D. melanogaster CYP6g2, which suggested a function in resistance to insecticides in this stingless bee.

Heat shock proteins (HSPs) have various functions in combating environmental stress and a variety of agents, such as temperature, dehydration, chemicals, heavy metals and other xenobiotics can regulate the expression of HSP (Sun and MacRae, 2005; Rinehart et al., 2006; Benoit et al., 2010). Several ESTs for HSPs were detected in the $M$. scutellaris fat body transcriptome. Two of these ESTs showed high similarity $\left(92 \%\right.$; E-value $\left.=7 \times 10^{-77}\right)$ with cytosolic HSP90 isoforms that have been associated with caste differentiation in A. mellifera (Xu et al., 2010). Some genes associated with caste differentiation in honeybees have been identified (Pinto et al., 2002; Cristino et al., 2006; Barchuk et al., 2007; Mackert et al., 2010), and caste differentiation in stingless bees has also been widely studied (Kerr, 1947; Kerr and Nielsen, 1966; Bonetti, 1984, 1995; Santana et al., 2006; Vieira et al., 2008).
An EST found in the fat body of M. scutellaris was similar to a putative farnesoic acid O-methyl-transferase (FAMeT). This putative enzyme catalyzes the synthesis of methylfarnesoate from farnesoic acid in the biosynthetic pathway of juvenile hormone in the corpora allata. Vieira et al. (2008) found that FAMeT of M. scutellaris (MsFAMeT) has different expression levels in castes, suggesting that this enzyme may be associated with the metabolism of juvenile hormone in this stingless bee. These findings suggest either that this enzyme is ambiguous in Melipona and can participate in other biochemical pathways or that it is not specific for juvenile hormone synthesis. Although no ESTs encoding for enzymes that degrade juvenile hormone were detected in the M. scutellaris fat body, RT-PCR and qPCR detected mRNAs for juvenile hormone esterase and juvenile hormone epoxide hydrolase (data not shown), which confirms the expression of these genes in this fat body.

In conclusion, we have identified 1728 ESTs from the fat body of M. scutellaris. In silico analysis of these ESTs has provided new insights into the physiological roles of this tissue in phenomena such as innate immunity, cellular proliferation, resistance to insecticides and environmental stress, and caste differentiation in stingless bees.

\section{Acknowledgments}

This work was supported by grants from the Brazilian research agencies Fundação de Amparo à Pesquisa de Minas Gerais (FAPEMIG - EDT 522/07 to JES and CBBAPQ-02128-10 to AMB), Conselho Nacional de Desenvolvimento Científico e Tecnológico (CNPq) and Coordenação de Aperfeiçoamento de Pessoal de Ensino Superior (CAPES). We thank Kevin Cloonan (University of California, Davis) for critically reviewing the English version of this manuscript.

\section{References}

Adams MD, Kelley JM, Gocayne JD, Dubnick M, Polymeropoulos $\mathrm{MH}$, Xiao H, Merril CR, Wu A, Olde B and Moreno RF (1991) Complementary DNA sequencing: Expressed sequence tags and human genome project. Science 252:1651-1656.

Akira S, Uematsu S and Takeuchi O (2006) Pathogen recognition and innate immunity. Cell 124:783-801.

Al-Shahrour F, Diaz-Uriarte R and Dopazo J (2004) FatiGO: A web tool for finding significant associations of Gene Ontology terms with groups of genes. Bioinformatics 20:578-580.

Altschul SF, Gish W, Miller W, Myers EW and Lipman DJ (1990) Basic local alignment search tool. J Mol Biol 215:403-410.

Altschul SF, Madden TL, Schäffer AA, Zhang J, Zhang Z, Miller W and Lipman DJ (1997) Gapped BLAST and PSI-BLAST: A new generation of protein database search programs. Nucleic Acids Res 25:3389-3402.

Amaral IMR, Neto JFM, Pereira GB, Franco MB, Beletti ME, Kerr WE, Bonetti AM and Ueira-Vieira C (2010) Circulating hemocytes from larvae of Melipona scutellaris 
(Hymenoptera, Apidae, Meliponini): Cell types and their role in phagocytosis. Micron 41:123-129.

Andrade GS, Serrão JE, Zanuncio JC, Zanuncio TV, Leite GLD and Polanczyk RA (2010) Immunity of an alternative host can be overcome by higher densities of its parasitoids Palmistichus elaeisis and Trichospilus diatraeae. PloS One 5:e13231.

Arrese EL and Soulages JL (2010) Insect fat body: Energy, metabolism and regulation. Annu Rev Entomol 55:207-225.

Azevedo DO, Zanuncio JC, Delabie JHC and Serrão JE (2011) Temporal variation of vitellogenin synthesis in Ectatomma tuberculatum (Formicidae, Ectatomminae) workers. J Insect Physiol 57:972-977.

Barchuk AR, Cristino AS, Kucharski R, Costa LF, Simões ZLP and Maleszka R (2007) Molecular determinants of caste differentiation in the highly eusocial honeybee Apis mellifera. BMC Dev Biol 7:e70.

Benoit JB, Lopez-Martinez G, Phillips ZP, Patrick KR and Denlinger DL (2010) Heat shock proteins contribute to mosquito dehydration tolerance. J Insect Physiol 56:151-156.

Bonetti AM (1984) Efeitos do hormônio juvenil no desenvolvimento ovariano de Melipona quadrifasciata. Rev Bras Biol 44:509-516.

Bonetti AM, Kerr WE and Matusita SH (1995) Effects of juvenile hormones I, II and III, in single and fractionated dosage in Melipona bees. Rev Bras Biol 55:113-120.

Chen Chih WR, Shaio MF and Cho WL (2007) A p38 MAP kinase regulates the expression of the Aedes aegypti defensin gene in mosquito cells. Insect Mol Biol 16:389-399.

Claudianos C, Ranson H, Johnson R, Biswas S, Schuler M, Berenbaum M, Feyereisen R and Oakeshott J (2006) A deficit of detoxification enzymes: Pesticide sensitivity and environmental response in the honeybee. Insect Mol Biol 15:615636.

Cristino A, Nunes F, Lobo C, Bitondi MMG, Simões ZLP, Da Fontoura Costa L, Lattorff H, Moritz R, Evans J and Hartfelder K (2006) Caste development and reproduction: A genome wide analysis of hallmarks of insect eusociality. Insect Mol Biol 15:703-714.

Cross TG, Scheel-Toellner D, Henriquez NV, Deacon E, Salmon M and Lord JM (2000) Serine/threonine protein kinases and apoptosis. Exp Cell Res 256:34-41.

Cruz-Landim C (1985) Histological and cytological studies on the fat body of the queen honeybee abdomen during the active oviposition phase. Rev Bras Biol 45:221-232.

Daborn PJ, Lumb C, Boey A, Wong W and Batterham P (2007) Evaluating the insecticide resistance potential of eight Drosophila melanogaster cytochrome $\mathrm{P} 450$ genes by transgenic over-expression. Insect Biochem Mol Biol 37:512519 .

Ewing B and Green P (1998) Base-calling of automated sequencer traces using Phred. II. Error probabilities. Genome Res 8:186-194.

Ewing B, Hillier LD, Wendl MC and Green P (1998) Base-calling of automated sequencer traces usingPhred. I. Accuracy assessment. Genome Res 8:175-185.

Feitosa FM, Calvo E, Merino EF, Durham AM, James AA, Bianchi AG, Marinotti O and Capurro ML (2006) A transcriptome analysis of the Aedes aegypti vitellogenic fat body. J Insect Sci 6:1-26.
Ivanova E and Staikova T (2007) Stage specificity in the expression of proteins of honey bee fat body (Apis mellifera L.) in the course of ontogenesis. J Cell Mol Biol 6:129-135.

Kavanagh K and Reeves EP (2004) Exploiting the potential of insects for in vivo pathogenicity testing of microbial pathogens. FEMS Microbiol Rev 28:101-112.

Kerr WE (1947) Estudo Sobre o Genero Melipona. USP Editora, São Paulo, 67 pp.

Kerr WE and Nielsen RA (1966) Evidences that genetically determined Melipona queens can become workers. Genetics 54:859-866

Kerr WE, Carvalho GA and Nascimento VA (1996) Abelha Uruçu: Biologia, Manejo e Conservação. Fundação Acangaú, Belo Horizonte, 144 pp.

Kim DH, Feinbaum R, Alloing G, Emerson FE, Garsin DA, Inoue H, Tanaka-Hino M, Hisamoto N, Matsumoto K, Tan M-W, et al. (2002) A conserved p38 MAP kinase pathway in Caenorhabditis elegans innate immunity. Science 297:623-626.

Kurella M, Hsiao L-L, Yoshida T, Randall JD, Chow G, Sarang SS, Jensen RV and Gullans SR (2001) DNA microarray analysis of complex biologic processes. J Am Soc Nephrol 12:1072-1078.

Leclerc V and Reichhart JM (2004) The immune response of Drosophila melanogaster. Immunol Rev 198:59-71.

Mackert A, Hartfelder K, Bitondi MMG and Simões ZLP (2010) The juvenile hormone ( $\mathrm{JH})$ epoxide hydrolase gene in the honey bee Apis mellifera genome encodes a protein which has negligible participation in $\mathrm{JH}$ degradation. J Insect Physiol 56:1139-1146.

Mansuy D (1998) The great diversity of reactions catalyzed by cytochromes P450. Comp Biochem Physiol C Pharmacol Toxicol Endocrinol 121:5-14.

Martins GF, Guedes BAM, Silva LM, Serrão JE, Fortes-Dias CL, Ramalho-Ortigão JM and Pimenta PFP (2011a) Isolation, primary culture and morphological characterization of oenocytes from Aedes aegypti pupae. Tissue Cell 43:83-90.

Martins GF, Ramalho-Ortigão JM, Lobo NF, Severson DW, McDowell MA and Pimenta PFP (2011b) Insights into the transcriptome of oenocytes from Aedes aegypti pupae. Mem Inst Oswaldo Cruz 106:308-315.

Nasonia Genome Working Group (2010) Functional and evolutionary insights from the genomes of three parasitoid Nasonia species. Science 327:343-348.

Ottaviani E, Malagoli D and Franceschi C (2011) The evolution of the adipose tissue: A neglected enigma. Gen Comp Endocrinol 174:1-4.

Paes de Oliveira VT and Cruz-Landim C (2003) Size of fat body trophocytes and the ovarian development in workers and queens of Melipona quadrifasciata anthidioides. Sociobiology 41:701-709.

Pinto LZ, Hartfelder K, Bitondi MMG and Simões ZLP (2002) Ecdysteroid titers in pupae of highly social bees relate to distinct modes of caste development. J Insect Physiol 48:783790.

Price DP, Seo SS, Kim JY and Park SY (2011) Anti-apoptotic protein TCTP controls the stability of the tumor suppressor p53. FEBS Lett 585:29-35.

Ribeiro C and Brehélin M (2006) Insect haemocytes: What type of cell is that? J Insect Physiol 52:417-429. 
Rinehart JP, Hayward SAL, Elnitsky MA, Sandro LH, Lee Jr RE and Denlinger DL (2006) Continuous up-regulation of heat shock proteins in larvae, but not adults, of a polar insect. Proc Natl Acad Sci USA 103:14223-14227.

Roma GC, Bueno OC and Camargo-Mathias MI (2010) Morphophysiological analysis of the insect fat body: A review. Micron 41:395-401.

Santana FA, Nunes FMF, Vieira CU, Machado MAMS, Kerr WE, Silva Jr WA and Bonetti AM (2006) Differentially displayed expressed sequence tags in Melipona scutellaris (Hymenoptera, Apidae, Meliponini) development. An Acad Bras Ciênc 78:69-75.

Sun Y and MacRae TH (2005) The small heat shock proteins and their role in human disease. FEBS J 272:2613-2627.

The Honeybee Genome Sequencing Consortium (2006) Insights into social insects from the genome of the honeybee Apis mellifera. Nature 443:931-949.

Tijet N, Helvig C and Feyereisen R (2001) The cytochrome P450 gene superfamily in Drosophila melanogaster: Annotation, intron-exon organization and phylogeny. Gene 262:189198.

Tzou P, De Gregorio E and Lemaitre B (2002) How Drosophila combats microbial infection: A model to study innate immunity and host-pathogen interactions. Curr Opin Microbiol 5:102-110.

Vieira CU, Bonetti AM, Simões ZLP, Maranhão AQ, Costa CS, Costa MCR, Siquieroli, ACS and Nunes FMF (2008) Farnesoic acid O-methyl transferase (FAMeT) isoforms: Con- served traits and gene expression patterns related to caste differentiation in the stingless bee, Melipona scutellaris. Arch Insect Biochem Physiol 67:97-106.

Wojda I, Kowalski P and Jakubowicz T (2004) JNK MAP kinase is involved in the humoral immune response of the greater wax moth larvae Galleria mellonella. Arch Insect Biochem Physiol 56:143-154.

Woodard SH, Fischman BJ, Venkat A, Hudson ME, Varala K, Cameron SA, Clark AG and Robinson GE (2011) Genes involved in convergent evolution of eusociality in bees. Proc Natl Acad Sci USA 108:7472-7477.

Xu PJ, Xiao JH, Xia QY, Murphy B and Huang DW (2010) Apis mellifera has two isoforms of cytoplasmic HSP90. Insect Mol Biol 19:593-597.

Zweiger G and Scott RW (1997) From expressed sequence tags to epigenomics: An understanding of disease processes. Curr Opin Biotechnol 8:684-687.

\section{Internet Resources}

EGassembler from Human Genome Center, http://egassembler.hgc.jp (accessed June 4, 2011).

Gene Ontology, http://www.geneontology.org (accessed June 11, 2011).

Associate Editor: Klaus Hartfelder

License information: This is an open-access article distributed under the terms of the Creative Commons Attribution License, which permits unrestricted use, distribution, and reproduction in any medium, provided the original work is properly cited. 